\title{
Optimization of electric field intensities produced by power lines using particle swarm algorithms
}

\author{
Krzysztof Król ${ }^{1 *}$, Wojciech Machczyński ${ }^{1}$, Krzysztof Budnik ${ }^{1}$, Jan Szymenderski ${ }^{1}$ \\ ${ }^{1}$ Poznań University of Technology, Institute of Electrical Engineering and Electronics, Piotrowo 3A, 60-965 Poznań, Poland
}

\begin{abstract}
The paper presents optimization of line parameters in order to reducing the intensity of the electric field with the use of particle swarm optimization (PSO). Simulations of the electric field intensity have been curried out for a different heights and distances for a building wall located in the vicinity of a power line.
\end{abstract}

\section{Introduction}

Transmission lines with high voltage levels generate large values of electric fields intensities which can affect the human being and the nearby objects. It is usually required to reduce the fields intensity produced by power lines. Therefore studies of calculation techniques to accurately predict the optimal distribution of electric field intensities is considered as necessary and important object of efforts to electric fields management in the vicinity of high voltage power lines.

The electric field intensity is a function of the line voltage, but its resolution depends on terrain conditions, wires deployment, wire suspension height, conductor lengths, phase order and phase voltage. The routes of power lines are designed in such a way that they bypass the urbanized areas, but often the lines pass near or over residential buildings. In the Regulation of the Minister of the Environment [1], the maximum permissible intensity of an electric field is defined as $10 \mathrm{kV} / \mathrm{m}$ for areas accessible to people, and for a place of residence $1 \mathrm{kV} / \mathrm{m}$.

The paper presents optimization of the electric field intensities occurring at different heights of a front face of a building located at different distances from the power line.

\section{Intensity of the electric field of a power line including the sag of wires}

Figure 1 shows the sag of a transmission line. A conductor of a span is divided into $n$ equal segments $\left(s_{l}\right.$, $\left.\mathrm{s}_{2}, \ldots s_{i-l}, s_{i}, s_{i+l}, s_{n}\right) . H$ is the maximum height of the conductors suspension, $h$ is the minimum height of the conductors suspension in the middle of the span, $S$ is the conductor sag, $S=H-h$. On each segment am electric charge with line density $\eta_{n}$ exists. The number of simulated charges must correspond to the number of defined segments. Each of the segments $\left(s_{1}, \ldots, s_{n}\right)$ can be described by the curve equation [2-4]:

$$
z^{\prime}\left(x^{\prime}\right)=h+2 \alpha \sinh ^{2}\left(\frac{x^{\prime}}{2 \alpha}\right)
$$

where $\alpha$ is related to the mechanical parameters of the line: $\alpha=T h / w$. Th is the mechanical stresses in the middle of the line, $w$ is the weight per unit of the length of the line.

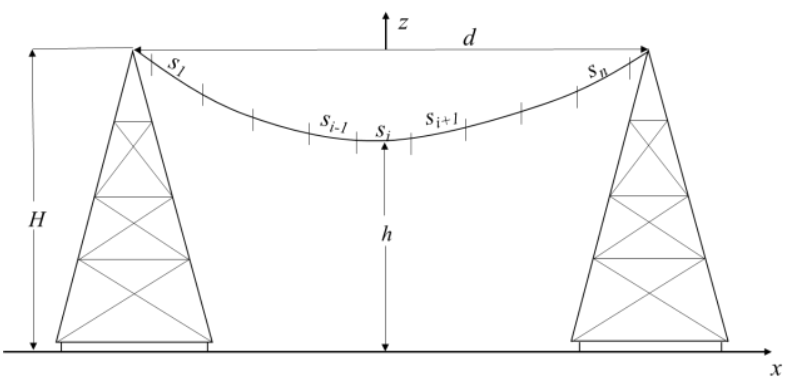

Fig. 1. Division of a power line conductor into $n$ segments.

The potential of the static electric field near power line at any observation point above the ground plane is determined by using the charge simulation method (CSM) and the metod of images $[3,5,6]$.

In the case where the power line consists of more than one conductor $(m=1,2, \ldots, M)$, the total intensity of the electric field at the observation point is calculated from the vector summation of the fields from all the transmission line conductors from the formula:

$$
\boldsymbol{E}_{\boldsymbol{T}}(x, y, z)=\sum_{m=1}^{M} \frac{1}{4 \pi \varepsilon_{0}}\left[\boldsymbol{I}_{3 m}-\boldsymbol{I}_{4 m}\right]
$$

$$
I_{3 m}=\int_{-d / 2}^{d / 2} \lambda_{s n}\left(r^{\prime}\right) \frac{\left[\left(x-x^{\prime}\right) \boldsymbol{a}_{x}+\left(y-y^{\prime}\right) \boldsymbol{a}_{y}+\left(z-z^{\prime}\right) \boldsymbol{a}_{z}\right] \cosh \left(\frac{x^{\prime}}{\alpha}\right)}{\left(\sqrt{\left(x-x^{\prime}\right)^{2}+\left(y-y^{\prime}\right)^{2}+\left(z-z^{\prime}\right)^{2}}\right)^{3}} d x^{\prime}(3)
$$

\footnotetext{
Corresponding author: krzykrol6@wp.pl
} 


$$
I_{4 m}=\int_{-d / 2}^{d / 2} \lambda_{s n}\left(r^{\prime}\right) \frac{\left[\left(x-x^{\prime}\right) a_{x}+\left(y-y^{\prime}\right) a_{y}+\left(z+z^{\prime}\right) a_{z}\right] \cosh \left(\frac{x^{\prime}}{\alpha}\right)}{\left(\sqrt{\left(x-x^{\prime}\right)^{2}+\left(y-y^{\prime}\right)^{2}+\left(z+z^{\prime}\right)^{2}}\right)^{3}} d x^{\prime}(4)
$$

where: $(x, y, z)$ are the coordinates of the observation point $P$, and $\left(x^{\prime}, y^{\prime}, z^{\prime}\right)$ coordinates of the source points, $\boldsymbol{a}_{\boldsymbol{x}}, \boldsymbol{a}_{\boldsymbol{y}}, \boldsymbol{a}_{z}$ are the unit vectors of the Cartesian coordinate system.

\section{Example}

The example presents a house with an area of $100 \mathrm{~m}^{2}$ and a height of $6 \mathrm{~m}$ which is located near power line as in Fig. 2. The chosen power line had a rated voltage of $220 \mathrm{kV}$ and was hung on the tower of type H52 (Fig. 3).

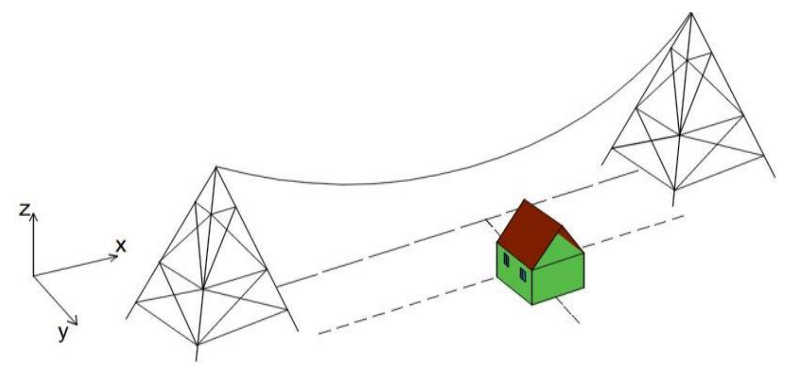

Fig. 2. Geometry of a system power line - house.
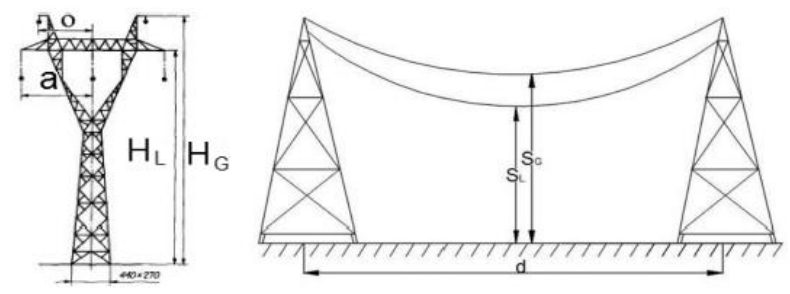

Fig. 3. Parameters of the $220 \mathrm{kV}$ line.

The electric fields intensity is calculated for different heights (1-6 m) of a front face of the building.

The plot of the intensity of the electric field is shown in Fig. 4. According to [1] the electrical field intensity can not exceed $1 \mathrm{kV} / \mathrm{m}$.

The maximum intensity of the electric field in the test area was $E_{\max }=30,3 \mathrm{kV} / \mathrm{m}$ and was calculated at a height of 6 meters and distance $5 \mathrm{~m}$, from the center of the line. The intensity of the electric field was about 30 times more the maximum recommended in the Regulation [1].

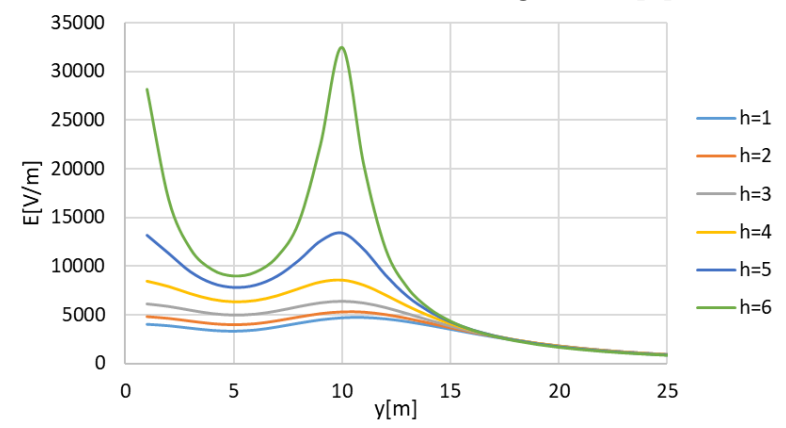

Fig. 4. Profile of the electric field intensity near the $220 \mathrm{kV}$ before optimization.
Optimization with a PSO $[3,7,8]$ was performed for the following assumptions: $6 \mathrm{~m} \leq a \leq 9 \mathrm{~m}, 18 \mathrm{~m} \leq H_{L} \leq$ $26,5 \mathrm{~m}, 4 \mathrm{~m} \leq o \leq 7 \mathrm{~m}, 28 \mathrm{~m} \leq H_{G} \leq 32 \mathrm{~m}, 20 \mathrm{~m} \leq S_{G} \leq$ $23 \mathrm{~m}, \mathrm{E}_{\max }<1 \mathrm{kV} / \mathrm{m}, \mathrm{H}_{\max }<60 \mathrm{~A} / \mathrm{m}$.

The plot of the intensity of the electric field after optimization is shown in Fig. 5.

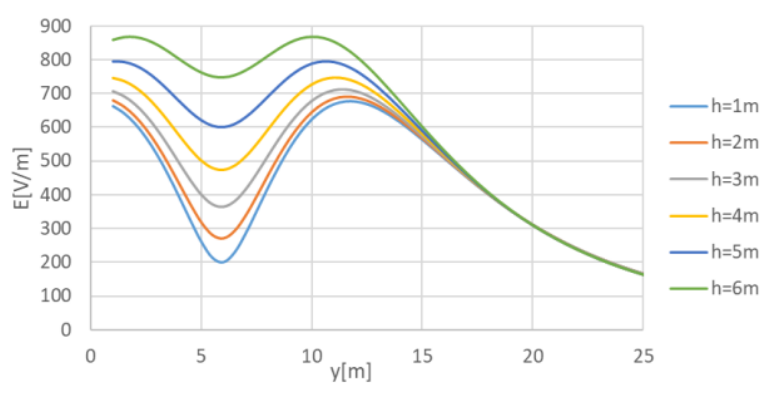

Fig. 5. Profile of the electric field intensity near the $220 \mathrm{kV}$ after optimization.

The time of calculating the electric field intensity using the PSO algorithm was 448,98 seconds. As a result of optimization the intensity of the electric field was reduced about 33 times.

\section{Conclusions}

The paper presents optimization of power line geometrical parameters aimed to reduce the intensity of the electric field intensity under an overhead power line with the use of a particle swarm optimization PSO.

It can be stated that the correlation between geometric parameters of the line and the value of the electric field intensity is very large. This fact should be taken into account as one of the parameters responsible for the safety of people permanently in the vicinity of power lines and in particular of the highest voltage lines, ex. when designing new installations or modifying existing ones.

The applied optimization methods can be a useful engineering and scientific tool in assessing the threat of the impact of electric field from overhead power lines on living organisms and nearby technical infrastructure.

\section{References}

1. Dz.U. 2003 nr 192 poz. 1883

2. R. Amiri, H. Hadi, M. Marich, Conference of Electrical In-sulation and Dielectric Phenomena, Kansas City, Missouri USA, 206-209 (2006)

3. K. Król, W. Machczyński, Arch. of Elect. Eng., 67, 829-843 (2018)

4. A. Ranković, Eur. Trans. on Elect. Pow., 27, 2, (2017)

5. W. Machczyński, XII Sem. z Pods. Elektr. i Teorii Obw., Gliwice-Wisła, 278-286 (1989)

6. H, Singer, H. Steinbigler, P. Weiss, IEEE Trans. on PAS, 93, 5, 1660-1667 (1974).

7. A.Z. Dein, Elect. Pow. and Ener. Sys., 198-210 (2014)

8. P. Foryś, 10th Inter. Conf. on Num. Meth. in Contin. Mech., Zilina, August 23-26, 13 (CD-ROM) (2005) 